\title{
Mechanism of G9a inhibitor BIX-01294 acting on U251 glioma cells
}

\author{
AI-SHUN GUO ${ }^{1}$, YI-QUN HUANG ${ }^{2}$, XU-DONG MA ${ }^{2}$ and RUI-SHENG LIN ${ }^{1}$ \\ Departments of ${ }^{1}$ Neurosurgery and ${ }^{2}$ Hematology, Zhangzhou Affiliated Hospital of Fujian Medical University, \\ Zhangzhou, Fujian 363000, P.R. China
}

Received August 4, 2015; Accepted August 16, 2016

DOI: $10.3892 / \mathrm{mmr} .2016 .5815$

\begin{abstract}
The present study aimed to investigate the differential expression and clinical significance of histone methyltransferase G9a, histone H3K9me2 and histone H3K9me1 in human brain glioma and adjacent tissue samples. It also aimed to observe the effect and mechanism of BIX-01294, as an inhibitor of methyltransferase G9a, on the proliferation, apoptosis, methylation of $\mathrm{H} 3 \mathrm{~K} 9$ and $\mathrm{H} 3 \mathrm{~K} 27$, and the acetylation in U251 glioma cells in vitro. The differential expression of methyltransferase G9a, histone H3K9me2 and histone $\mathrm{H} 3 \mathrm{~K} 9 \mathrm{mel}$ in in human brain glioma and adjacent tissues were analyzed by immunohistochemistry, a growth curve of U251 cells following treatment with BIX-01294 was determined using the MTT assay. In addition, the apoptosis percentage of U251 cells was analyzed by TUNEL assay and the expression levels of apoptosis-associated proteins, including B-cell lymphoma 2 (Bcl-2), Bcl-2-associated X protein (Bax), caspase-9 and caspase-3, and the acetylation of histones, including H3K27me1, H3K27me2 and H3 in U251 were analyzed by western blot following BIX-01294 treatment. The positive rate of G9a in glioma tissues was $86 \%$ (43/50), which was significantly different from $42 \%(21 / 50)$ in adjacent tissues $(\mathrm{P}<0.01)$. The positive rate of $\mathrm{H} 3 \mathrm{~K} 9 \mathrm{me} 2$ in glioma tissues was $82 \%$ (41/50), which was significantly different from $38 \%(19 / 50)$ in adjacent tissues $\left(\chi^{2}=18.38\right.$; $\mathrm{P}<0.01)$. The expression of G9a and H3K9me2 were associated with the World Health Organization (WHO) glioma grade. The positive rate of $\mathrm{H} 3 \mathrm{~K} 9 \mathrm{mel}$ in glioma tissues was $54 \%(27 / 50)$ and $44 \%(22 / 50)$ in adjacent tissues, though this result was not significantly different $\left(\chi^{2}=1.21, \mathrm{P}>0.05\right)$. BIX-01294 inhibited the proliferation of U251, downregulated expression of Bcl-2, and upregulated expression of Bax, caspase-3 and caspase-9, and induced apoptosis of U251.
\end{abstract}

Correspondence to: Dr Xu-Dong Ma, Department of Hematology, Zhangzhou Affiliated Hospital of Fujian Medical University, 59 Shengli Road, Zhangzhou, Fujian 363000, P.R. China E-mail: maxuong_1@163.com

Key words: G9a, glioma, histone lysine demethylase, histone methylation, apoptosis, epigenetics
BIX-01294 downregulated H3K9me1, H3K9me2, H3K27me1 and $\mathrm{H} 3 \mathrm{~K} 27 \mathrm{me}$, however, it did not affect the acetylation of $\mathrm{H} 3 \mathrm{~K} 9 \mathrm{me} 3$ and $\mathrm{H} 3$. High expression of G9a and $\mathrm{H} 3 \mathrm{~K} 9 \mathrm{me} 2$ in glioma tissue samples was associated with the WHO grade, which indicated that $\mathrm{G} 9 \mathrm{a}$ and $\mathrm{H} 3 \mathrm{~K} 9 \mathrm{me} 2$ may promote generation and development of glioma. BIX-01294 inhibited proliferation and induced apoptosis of glioma cells, changes in methylation of $\mathrm{H} 3 \mathrm{~K} 9$ and $\mathrm{H} 3 \mathrm{~K} 27$ resulting in conformational changes of chromosome may be an underlying mechanism. BIX-01294 may be a potential novel therapeutic agent in the treatment of glioma.

\section{Introduction}

Histone methylation is conducted by the coordination of specific histone methyltransferase and demethylase, as a reversible dynamic process. The abnormal expression of histone methyltransferase and demethylase are important in the generation and development of glioma. It has been demonstrated that there were marked changes to expression of histone methyltransferases, including histone-lysine-N-methyltransferase SETD7, histone-lysine $\mathrm{N}$-methyltransferase 2A and myeloid/lymphoid or mixed-lineage leukemia 4, and to demethylases, including lysine-specific demethylase $2 \mathrm{~A}$ and lysine-specific demethylase $2 \mathrm{~B}$ in glioma cells (1). G9a, as the important methyltransferase of euchromatin, is important in the regulation of epigenetic inheritance. Huang et al (2) demonstrated that G9a and G9a-like protein 1 (GLP) may methylate tumor suppressor gene TP53, resulting in methylated TP53, which has no activity (2). H3K9 methylation induced by G9a may hold the ability of transcriptional inhibition. However, H3K9 methylation is important in transcriptional silencing, $\mathrm{X}$ chromatin deactivation and tumor generation and development. BIX-01294 is an artificial inhibitor of G9a with high selectivity. Kondo et al (3) demonstrated that following BIX-01294 treatment, the activity of G9a and H3K9 methylation decreased, leading to a decrease in chromosome stability, an increase in the apoptosis of tumor cells and cycle arrest (3).

The present study investigated the differential expression and clinical significance of histone methylase G9a, histone H3K9me2 and histone H3K9me1 in human brain glioma and adjacent tissues. By observing the influence of BIX-01294 on biological changes, histone methylation and acetylation in U251 cells, a possible mechanism was also investigated. 


\section{Materials and methods}

Subjects. All the patients (20 males and 21 females; mean age, 34.6) were hospitalized for neurosurgery in Zhangzhou Affiliated Hospital of Fujian Medical University (Zhangzhou, China) between January 2010 to June 2013. All the patients were diagnosed with glioma and underwent complete follow-up treatment, without any therapy received prior to surgery. The data, including pathological specimens and clinical materials were collected. According to the World Health Organization (WHO) classification standard of central nervous system neoplasms (4), the patients were graded into WHO I (8 patients), WHO II (21 patients), WHO III (15 patients) and WHO IV (6 patients). The tumor specimens and samples from the junctional area between the tumor and normal brain tissue were collected to serve as the experimental group and control group. Written informed consent was obtained from the participants prior to the start of the study. This study was approved by the Ethics Committee of Zhangzhou Affiliated Hospital of Fujian Medical University.

Agents. BIX-01294 was obtained from Sigma-Aldrich (Merck Millipore, Darmstadt, Germany). Fetal bovine serum (FBS) was obtained from Hangzhou Sijiqing Bioengineering Material Co., Ltd., Hangzhou, China. Antibodies against G9a (cat. no. 09-071) H3K9me1 (cat. no. 07-450), H3K9me2 (cat. no. 16-187), H3K9me3 (cat. no. 07-442), H3K27me1 (cat. no. 07-448), H3K27me2 (cat. no. 07-452), Acteylated (Act)-H3 (cat. no. 07-677-I), caspase-9 (cat.no.05-672), caspase-3 (cat. no. 05-654), B-cell lymphoma 2 (Bcl-2; cat. no. 05-826), $\mathrm{Bcl}-2$-associated $\mathrm{X}$ protein (Bax; cat. no. AB2915) and $\beta$-actin (cat. no. 04-1116) were obtained from Upstate Biotechnology, Inc. (Lake Placid, NY, USA) and used at dilutions between 1:200-1:500. Goat anti-rabbit (cat. no. sc-3837) and goat anti-mouse (cat. no. sc-395758) antibodies were obtained from Santa Cruz Biotechnology, Inc. and used at dilutions 1:2,000-1:5,000.

Cell culture. The U251 human glioma cell line was obtained from Shanghai Institute for Biological Sciences, Chinese Academy of Sciences (Shanghai, China). RPMI 1640 was obtained from Gibco (Thermo Fisher Scientific Inc., Waltham, MA, USA), containing 10\% FBS and $2 \mathrm{mM}$ L-glutamine. $\mathrm{U} 251$ cells were cultured at $37^{\circ} \mathrm{C}$ with saturated humidity and $5 \% \mathrm{CO}_{2}$. The cells were passaged every 3 to 4 days, with $0.25 \%$ trypsin digesting for 2-3 min followed by seeding of the cell suspension to the required concentration. Prior to seeding, the activity of U251 cells was detected by trypan blue staining.

Detection of G9a, H3K9me2 and H3K9mel expression in glioma and adjacent tissues. The proteins were detected using the streptavidin-peroxidase method (5). G9a (1:200), H3K9me2 (1:300) and H3K9me1 (1:300) antibodies were used. The results of the immunohistochemistry were judged by the semi-quantitative integral method, according to the sum of the color strength and the percentage of stained cells. Color strength grade: Without staining, 0; weak staining, 1; moderate staining, 2; and strong staining, 3. Coloring percentage: Without staining, $0 ;<25 \%, 1 ; 25-50 \%, 2 ; 50-75 \%$, 3 ; and $>75 \%$, 4 . Sum of the two: 0 , negative; $1-2,+$ (negative);
3-4, ++ (positive); 5-6, +++ (positive); and 7, ++++ (positive). All the data were evaluated by experienced pathologists using double blinding.

MTS assay to detect the cell growth curve following different concentrations of BIX-01294. Cells in the logarithmic growth phase were seeded in a 96-well plate (Costar; Corning Incorporated, Corning, NY, USA) at a concentration of $1.0 \times 10^{5} / \mathrm{ml}(100 \mu \mathrm{l}$ each well). BIX-10294 was added and the concentration adjusted to $0,1,2,4$ and $8 \mu \mathrm{mol} / 1$ with 6 wells for each group. After $24 \mathrm{~h}, 48 \mathrm{~h}$ and $72 \mathrm{~h}$ at $37^{\circ} \mathrm{C}, 100 \mu \mathrm{l}$ MTS ( $5 \mathrm{mg} / \mathrm{ml}$; Sigma-Aldrich; Merck Millipore) was added and incubated for $4 \mathrm{~h}$ at $37^{\circ} \mathrm{C}$. The cells were centrifuged at $800 \times g$ for $5 \mathrm{~min}$ and the supernatant discarded. DMSO (100 $\mu \mathrm{l}$; Sigma-Aldrich; Merck Millipore) was added and mixed fully. The absorbance (value A) was detected at wavelengths of 492 and $630 \mathrm{~nm}$ using a microplate reader. The cell proliferation rate was calculated according to the $0 \mu \mathrm{M}$ (blank). Cell proliferation rate $(\%)=\left(\mathrm{A}_{\text {experiment }}-\mathrm{A}_{\text {blank }}\right) /\left(\mathrm{A}_{\text {control }}-\mathrm{A}_{\text {blank }}\right) \times 100 \%$. Repeated totally 3 times.

Apoptosis detection by TUNEL method. U251 cells in the logarithmic growth phase were seeded on 6-well plates at $1 \times 10^{6}$ cells per well, a cover glass was also placed in each well. After $24 \mathrm{~h}, \mathrm{BIX}-01294$ was added, the concentration was adjusted to $0,2,4$ and $8 \mu \mathrm{mol} / 1$ and the cells were incubated for $24 \mathrm{~h}$ at $37^{\circ} \mathrm{C}$. The TUNEL assay was conducted according to the manufacturer's protocols (DeadEnd ${ }^{\mathrm{TM}}$ Fluorometric TUNEL System; Promega Corporation, Madison, WI, USA) and cells were imaged using light microscopy.

Westernblotting to detect the changes of apoptosis-associated proteins following BIX-01294 treatment. The cells were centrifuged and collected following treatment for $24 \mathrm{~h}$. The cells were washed twice with PBS. Lysis buffer $(100 \mu \mathrm{l})$ and $1 \mu 1$ enzyme inhibitor were added to $1 \times 10^{6}$ cells on ice for $30 \mathrm{~min}$. The cells were then centrifuged at $10,000 \mathrm{xg}$, at $4^{\circ} \mathrm{C}$ for $10 \mathrm{~min}$ to extract the protein and protein quantification was conducted using the bicinchoninic acid method. The proteins (20 $\mu \mathrm{g}$ per lane) were separated by $12 \%$ SDS-PAGE gel electrophoresis and transferred to a polyvinylidene fluoride membrane (EMD Millipore, Billerica, MA, USA). Following transfer, membranes were blocked with $5 \%$ non-fat milk for $1 \mathrm{~h}$ at room temperature, and incubated with primary antibodies, H3K9me (1:500), H3K9me2 (1:500), H3K9me3 (1:500), H3K27me (1:1,000), H3K27me2 (1:1,000), Act-H3 (1:2,000), caspase 9 (1:600), caspase 3 (1:600), Bcl-2 (1:500) and $\mathrm{Bax}$ (1:500), at $4^{\circ} \mathrm{C}$ overnight. The membrane was then washed with Tris-buffered saline and goat anti-mouse secondary antibodies $(1: 5,000)$ were added and incubated for $1 \mathrm{~h}$ at room temperature. Following washing with TBS, the proteins were analyzed by chemiluminescence using $\beta$-actin as a loading control. The images were analyzed by AlphaDigiDoc imaging analysis software (version 7.1; Alpha Innotec, Kasendorf, Germany).

Statistical analysis. Data are presented as the mean \pm standard deviation. All the data were analyzed by SPSS 13.0 software (SPSS, Inc., Chicago, IL, USA). Homogeneity of variance and a normality test were conducted and one-way analysis of 
Table I. Differential expression of histone methylase G9a in glioma and adjacent tissues.

\begin{tabular}{lcccc}
\hline Group & $\begin{array}{c}\text { Cases } \\
(\mathrm{n})\end{array}$ & $\begin{array}{c}\text { Positive } \\
(\mathrm{n})\end{array}$ & $\begin{array}{c}\text { Positive rate } \\
(\%)\end{array}$ & $\mathrm{P}$ \\
\hline Glioma tissue & 50 & 43 & 86.00 & \\
Adjacent tissue & 50 & 21 & 42.00 & $<0.01$ \\
\hline
\end{tabular}

Table II. Differential expression of histone methylase G9a in different glioma tissue.

\begin{tabular}{|c|c|c|c|c|c|}
\hline \multirow{2}{*}{$\begin{array}{l}\text { WHO } \\
\text { stage }\end{array}$} & \multirow[b]{2}{*}{ Cases $(\mathrm{n}=)$} & \multirow[b]{2}{*}{ Positive $(n=)$} & \multicolumn{3}{|c|}{ Positive } \\
\hline & & & ++ & +++ & ++++ \\
\hline I & 8 & 5 & 4 & 1 & 0 \\
\hline II & 21 & 18 & 8 & 7 & 3 \\
\hline III & 15 & 14 & 5 & 6 & 3 \\
\hline IV & 6 & 6 & 0 & 2 & 4 \\
\hline
\end{tabular}

WHO, World Health Organization.

Table III. Differential expression of H3K9me2 in glioma and adjacent tissues.

\begin{tabular}{lcccc}
\hline Group & $\begin{array}{c}\text { Cases } \\
(\mathrm{n})\end{array}$ & $\begin{array}{c}\text { Positive } \\
(\mathrm{n})\end{array}$ & $\begin{array}{c}\text { Positive rate } \\
(\%)\end{array}$ & $\mathrm{P}$ \\
\hline Glioma tissue & 50 & 41 & 82.00 & \\
Adjacent tissue & 50 & 19 & 38.00 & $<0.01$ \\
\hline
\end{tabular}

Table IV. Differential expression of H3K9me2 in different glioma tissue samples.

\begin{tabular}{lrrrrr}
\hline & & & & \multicolumn{3}{c}{ Positive } \\
\cline { 4 - 6 } WHO & & & & & \\
stage & Cases (n) & Positive (n) & ++ & +++ & ++++ \\
\hline I & 8 & 4 & 3 & 1 & 0 \\
II & 21 & 18 & 7 & 5 & 6 \\
III & 15 & 13 & 4 & 5 & 4 \\
IV & 6 & 6 & 0 & 3 & 3 \\
\hline
\end{tabular}

WHO, World Health Organization.

variance was used to analyze the results. $\mathrm{P}<0.05$ was considered to indicate a statistically significant difference.

\section{Results}

G9a is differentially expressed in glioma and adjacent tissues. In glioma tissues, the positive rate of G9a was $86 \%(43 / 50)$, which was significantly higher than that in the adjacent tissues,
Table V. Differential expression of H3K9me1 in glioma and adjacent tissues.

\begin{tabular}{lcccc}
\hline Group & $\begin{array}{c}\text { Cases } \\
(\mathrm{n})\end{array}$ & $\begin{array}{c}\text { Positive } \\
(\mathrm{n})\end{array}$ & $\begin{array}{c}\text { Positive rate } \\
(\%)\end{array}$ & $\mathrm{P}$ \\
\hline Glioma tissue & 50 & 27 & 54.00 & \\
Adjacent tissue & 50 & 22 & 44.00 & $<0.01$ \\
\hline
\end{tabular}

Table VI. Differential expression of H3K9me1 in different glioma tissue samples.

\begin{tabular}{lccccc}
\hline & & & & \multicolumn{3}{c}{ Positive } \\
\cline { 4 - 6 } WHO & Cases (n) & Positive (n) & ++ & +++ & ++++ \\
\hline I & 8 & 4 & 1 & 1 & 2 \\
II & 21 & 12 & 4 & 5 & 3 \\
III & 15 & 8 & 2 & 3 & 3 \\
IV & 6 & 3 & 1 & 0 & 2 \\
\hline
\end{tabular}

WHO, World Health Organization.

$42 \%\left(21 / 50 ; \chi^{2}=19.14, \mathrm{P}<0.01\right.$; Table I). In grade I glioma tissues, G9a expression included 4 classified as,++ 1 classified as +++ and 0 classified as ++++ , grade II including 8 classified as,++ 7 classified as +++ and 3 classified as ++++ , grade III including 5 classified as,++ 6 classified as +++ and 3 classified as ++++ , and grade IV including 2 classified as +++ and 4 classified as ++++ . There were significant differences in the differential expression among different grades of glioma $(\mathrm{F}=37.52, \mathrm{P}<0.01)$. The higher WHO grade was associated with higher G9a expression intensity (Table II).

H3K9me2 is differentially expressed in glioma and adjacent tissues. The positive rate of $\mathrm{H} 3 \mathrm{~K} 9 \mathrm{me} 2$ in glioma tissues was $82 \%$ (41/50), which was significantly increased from $38 \%$ $(19 / 50)$ in adjacent tissues $\left(\chi^{2}=18.38, P<0.01\right.$; Table III $)$. In grade I glioma tissue, H3K9me 2 expression included 3 classified as,++ 1 classified as +++ and 0 classified as ++++ , grade II including 7 classified as,++ 5 classified as +++ and 6 classified as ++++ , grade III including 4 classified as ++ , 5 classified as +++ and 4 classified as ++++ , and grade IV including 3 classified as +++ and 3 classified as ++++ . There were significant differences in the differential expression among different grades of glioma $(\mathrm{F}=30.28, \mathrm{P}<0.01)$. Higher WHO grade was associated with higher $\mathrm{H} 3 \mathrm{~K} 9 \mathrm{me} 2$ expression intensity (Table IV).

H3K9mel is differentially expressed in glioma and adjacent tissues. The positive rate of $\mathrm{H} 3 \mathrm{~K} 9 \mathrm{mel}$ in in glioma tissues was $54 \%$ (27/50) which was not significantly different from the adjacent tissues were the positive rate was $44 \%(22 / 50)$ in adjacent tissues $\left(\chi^{2}=1.21, P>0.05\right.$; Table $\left.V\right)$. In grade I glioma tissues, H3K9me2 expression included 1 classified as ++ , 1 classified as +++ and 2 classified as ++++ , grade II including 4 classified as,++ 5 classified as +++ and 3 classified as ++++ , 

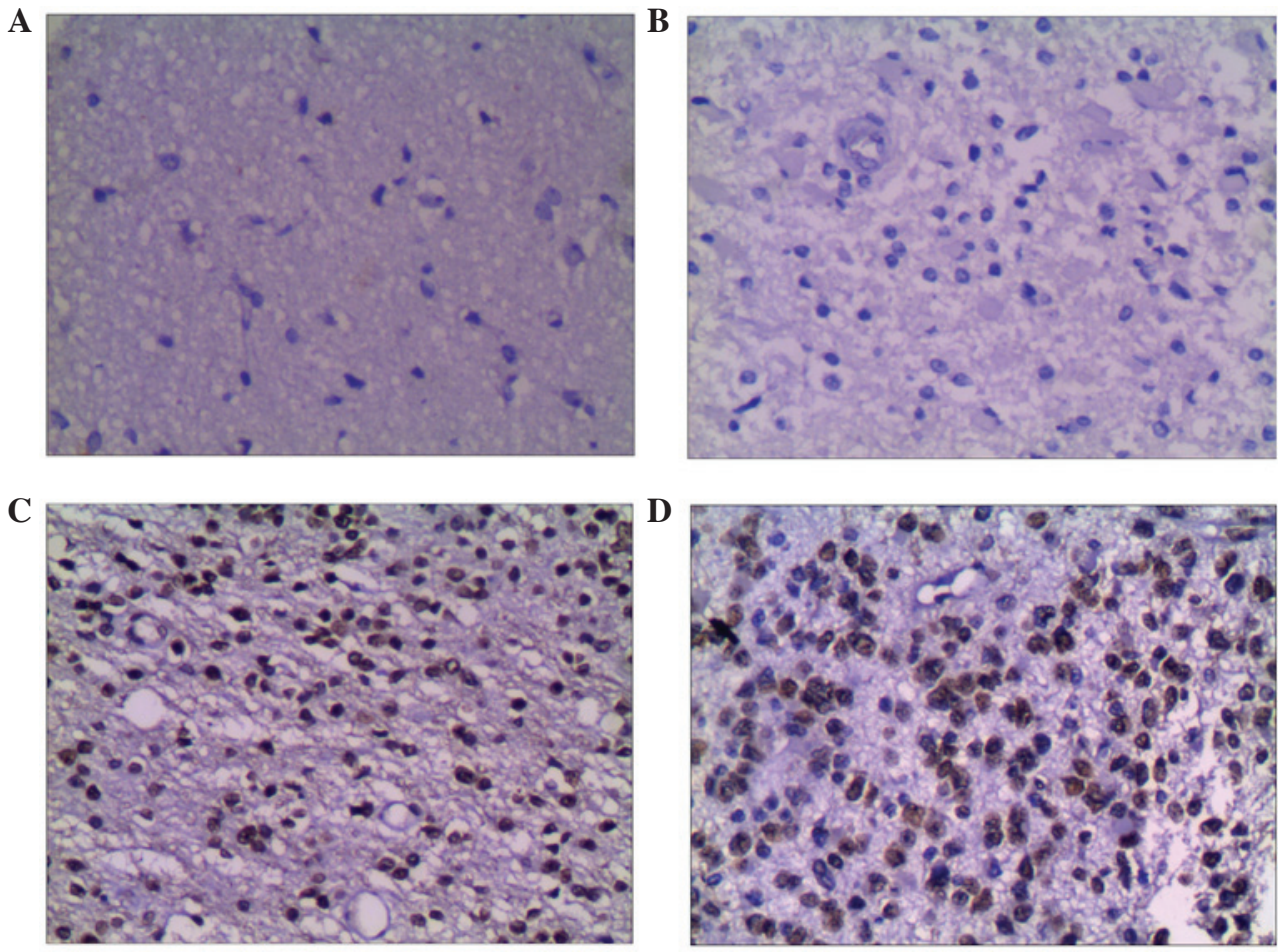

Figure 1. Expression of G9a in glioma and adjacent tissues (Olympus BX41; magnification, x200). (A) Negative result for G9a in adjacent tissues. (B) Negative result for G9a in grade I glioma. (C) Positive result for G9a in grade II glioma. (D) Positive result for G9a in grade IV glioma. G9a, histone methyltransferase G9a.

grade III including 2 classified as,++ 3 classified as +++ and 3 classified as ++++ , and grade IV including 1 classified as +++ and 2 classified as ++++. There were no significant differences in the differential expression among different grades of glioma ( $\mathrm{F}=1.28, \mathrm{P}>0.05$; Tables V and VI, Figs. 1-3).

BIX-01294 inhibited the proliferation of U251 cells. Following treatment with different concentrations of BIX-01294 (1, 2, 4 and $8 \mu \mathrm{mol} / \mathrm{l}$ ) for $24 \mathrm{~h}$, the proliferation rates of U251 cells were $94.12 \pm 3.41,78.83 \pm 2.25,53.68 \pm 2.54$ and $21.04 \pm 2.07 \%$, respectively. As the concentration increased, the proliferation inhibition rate increased and the proliferation rate decreased (Fig. 4). After $24 \mathrm{~h}, 48 \mathrm{~h}$ and $72 \mathrm{~h}$ of BIX-01294 treatment, the proliferation of $\mathrm{U} 251$ cells decreased. The proliferation rate also decreased in a time-dependent manner.

BIX-01294 induced apoptosis of U251 cells. Following treatment with different concentrations of BIX-01294 (1, 2, 4 and $8 \mu \mathrm{mol} / \mathrm{l})$ for $24 \mathrm{~h}$, the apoptosis rates of U251 cells were $3.67 \pm 1.42,16.42 \pm 5.18,35.18 \pm 3.26$ and $57.52 \pm 4.37 \%$, respectively, which indicates apoptosis rates significantly increased in a concentration-dependent manner ( $\mathrm{F}=32.52, \mathrm{P}<0.01$; Fig. 5).

BIX-01294 altered expression levels of apoptosis-associated proteins in U251 cells. Following treatment different concentration of BIX-01294 $(1,2,4$ and $8 \mu \mathrm{mol} / \mathrm{l})$ for $24 \mathrm{~h}$, the proteins were analyzed by western blotting and AlphaDigiDoc image analysis. Bcl-2 expression was demonstrated to be downregulated, while Bax, caspase-9 and caspase-3 were upregulated. All the gray values of the protein bands were compared with $\beta$-actin and statistically compared to the $0 \mu \mathrm{mol} / 1$ (blank group), indicating significant differences $(\mathrm{P}<0.05$, Fig. 6$)$.
BIX-01294 affects the methylation of H3K9 and H3K27, and the acetylation of $\mathrm{H} 3$. Following treatment with different concentrations of BIX-01294 (1, 2, 4 and $8 \mu \mathrm{mol} / \mathrm{l})$ for $24 \mathrm{~h}$, the monomethylation and dimethylation of H3K9 decreased, while the trimethylation was not markedly influenced, which indicates there was activity for monomethylation and dimethylation but reduced activity for trimethylation. G9a was also demonstrated to exert an effect on the first and second methylation of H3K27. Following treatment with different concentrations of BIX-01294 (1, 2, 4 and $8 \mu \mathrm{mol} / \mathrm{l})$ for $24 \mathrm{~h}$, there were no marked changes to $\mathrm{H} 3$ acetylation (Fig. 7).

\section{Discussion}

Histone methylation is an important regulatory mechanism in changing chromatin structure and transcription, which is associated with the generation and development of different types of tumor. H3K9 monomethylation, dimethylation and trimethylation indicate transcriptional inhibition. The trimethylation of $\mathrm{H} 3 \mathrm{~K} 9$ was associated with the closed structure of heterochromatin, while H3K9 dimethylation was associated with autosomal silencing (6). Stewart et al (7) demonstrated that $\mathrm{H} 3 \mathrm{~K} 9$ downregulated acetylation of $\mathrm{H} 3$ and $\mathrm{H} 4$, and deacetylated $\mathrm{H} 3$ and $\mathrm{H} 4$, which inhibited transcription and induced gene silencing. However, in endotoxin-tolerant THP-1 cells, G9a bound to the promoter region of $T N F \alpha$, to promote dimethylation of H3K9 and enriched DNMTa/3b, which promoted DNA methylation and inhibited $T N F \alpha$ transcription (8). H3K9 hypermethylation in the promoter region of the suppressor gene led to suppressor gene silencing, which is associated with the generation of tumors. Following treatment with 5-Aza-Dc in different types of gastric cancer cells, the 

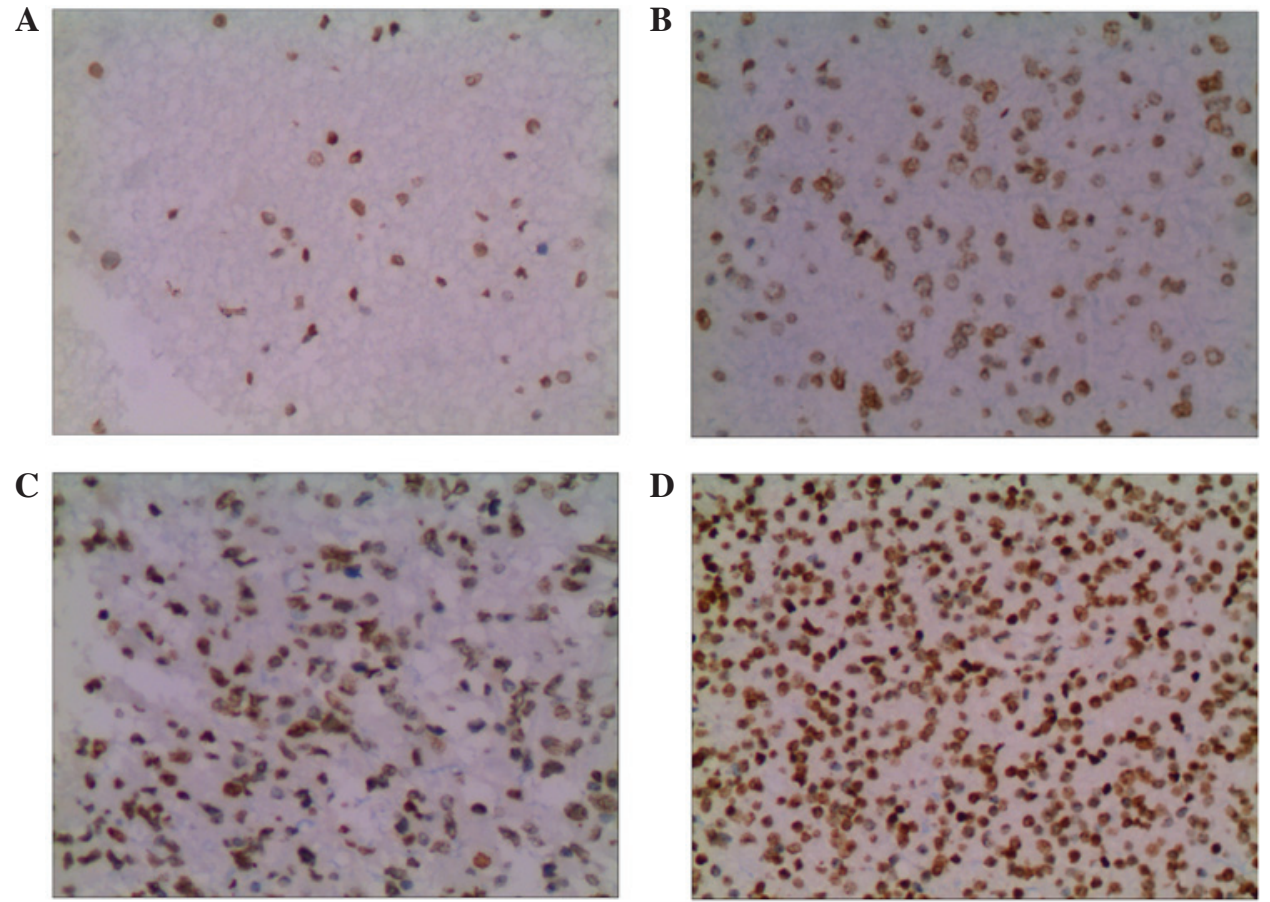

Figure 2. Expression of H3K9me2 in glioma and adjacent tissues (Olympus BX41; magnification, x200). (A) Positive H3K9me2 in adjacent tissues. (B) Positive H3K9me2 in grade II glioma. (C) Positive H3K9me2 in grade III glioma. (D) Positive H3K9me2 in grade IV glioma.
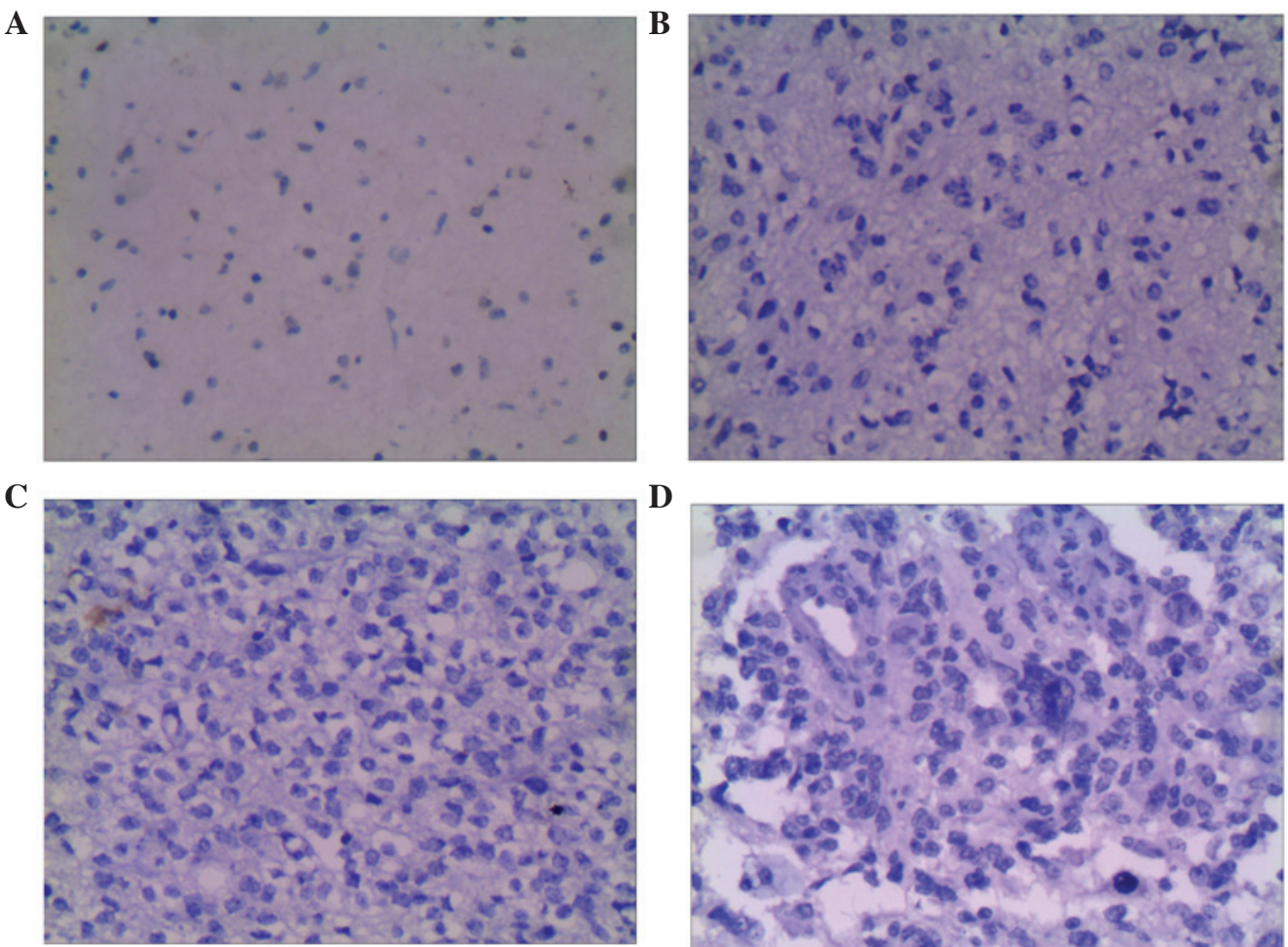

Figure 3. Expression of H3K9mel in glioma and adjacent tissues (Olympus BX41; magnification, x200). (A) Negative H3K9me in adjacent tissues. (B) Negative H3K9me in grade II glioma. (C) Negative H3K9me in grade III glioma. (D) Negative H3K9me in grade IV glioma.

dimethylation of H3K9 decreased, DNA was demethylated and $P 16$ expression was induced (9).

A previous study demonstrated that in gastric carcinoma, histone methyltransferase Suv39H1 and H3K9 trimethylation were highly expressed (10). Further studies demonstrated that Suv39H1 and H3K9 methylation were associated with tumor differentiation, invasive depth and lymph node metastasis, which indicated that the two may possibly promote the generation, development, invasion and metastasis of gastric carcinoma $(11,12)$. In the present study, the positive rate of H3K 9me2 in glioma tissue was $82 \%$ (41/50), which was significantly different to the $38 \%$ (19/50) in adjacent tissue 


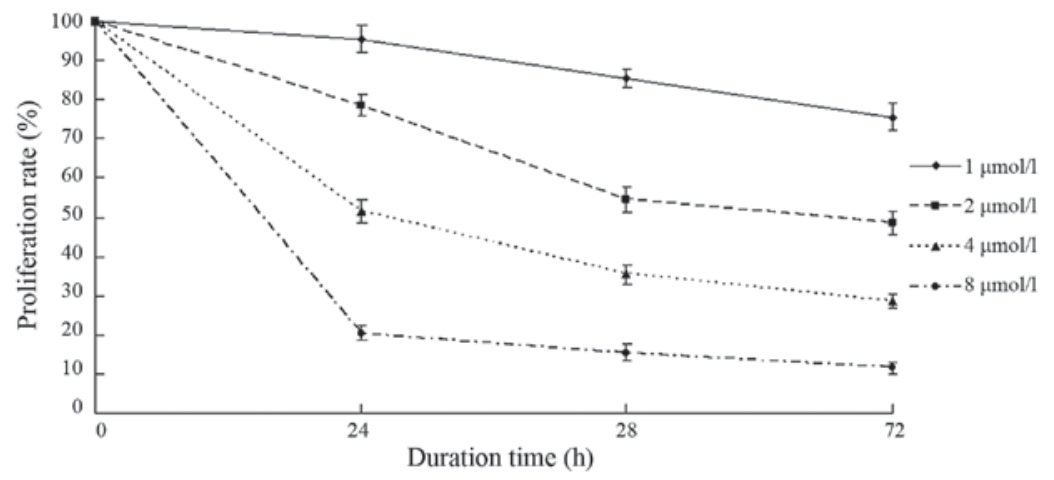

Figure 4. The changes of proliferation rate following treatment with different concentrations of BIX-01294.
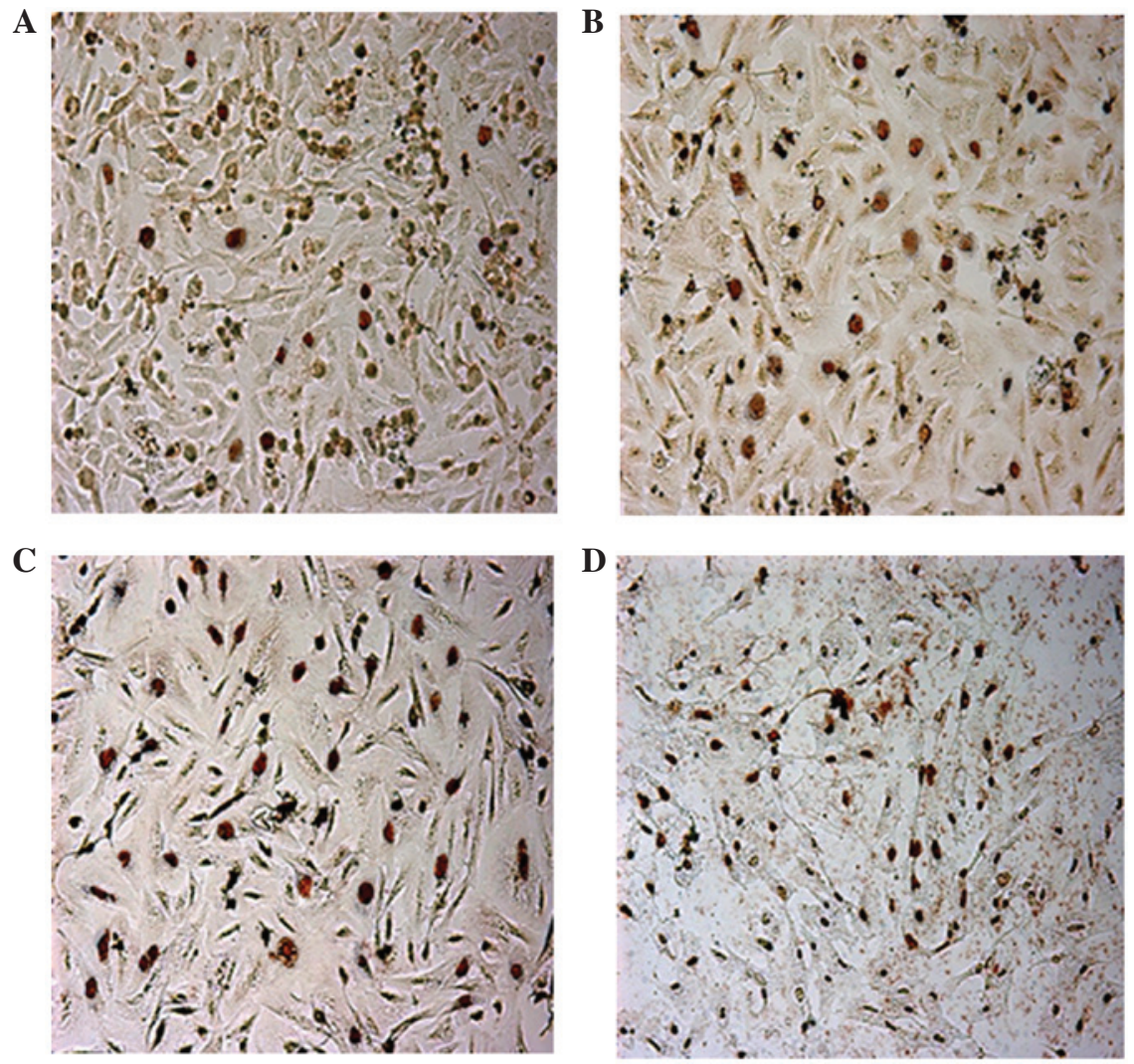

Figure 5. Change in of apoptosis rate following treatment with BIX-01294 for $24 \mathrm{~h}$. The apoptotic cells were TUNEL positive as observed by light microscopy, and the apoptotic nuclei were stained yellow-brown and dark brown. Treatment with (A) $0 \mu \mathrm{mol} / 1$, (B) $2 \mu \mathrm{mol} / 1$, (C) $4 \mu \mathrm{mol} / 1$ and (D) $8 \mu \mathrm{mol} / 1$ resulted in the following changes: (A) $3.67 \pm 1.42 \%$, (B) $16.42 \pm 5.18 \%$, (C) $35.18 \pm 3.26 \%$ and (D) $57.52 \pm 4.37 \%$.

$\left(\chi^{2}=18.38, \mathrm{P}<0.01\right)$. The positive rate of $\mathrm{H} 3 \mathrm{~K} 9 \mathrm{me} 2$ was associated with higher WHO glioma grade. However, the positive rate of $\mathrm{H} 3 \mathrm{~K} 9 \mathrm{mel}$ in glioma tissue was 54\% (27/50), and 44\% $(22 / 50)$ in adjacent tissue $\left(\chi^{2}=1.21, P>0.05\right)$. These results indicated that $\mathrm{H} 3 \mathrm{~K} 9 \mathrm{me} 2$ was associated with the generation and development of glioma, while H3K9mel was not important in the generation and development of glioma. H3K9me2 may be an indicator of glioma severity and prognosis.

Lysine methylation of histone was completed by the catalysis of histone lysine methyltransferases, while G9a is the predominant methyltransferase of $\mathrm{H} 3 \mathrm{~K} 9$. In euchromatin, G9a catalyzed monomethylation and dimethylation of $\mathrm{H} 3 \mathrm{~K} 9$, while methylated H3K27 in vitro (13). G9a gene deletion led to a decrease in $\mathrm{H} 3 \mathrm{~K} 9 \mathrm{me} 2$ in the nuclear peripheral region, while some control of gene silencing was lost (14). Previous studies have demonstrated that the abnormal expression of histone methyltransferase and histone demethylase were associated with the generation and development of tumors (15). Chen et al (16) observed that the mRNA and protein expression levels of histone methyltransferase $G 9$ gene in extrahepatic bile duct carcinoma were increased compared with the control group, which were positively associated with lymph node metastasis and TNM staging (16). The present study determined that the positive rate of G9a in glioma tissues was $86 \%$ (43/50), which was significantly different from $42 \%$ (21/50) in adjacent tissues $(\mathrm{P}<0.01)$. Increased $\mathrm{H} 3 \mathrm{~K} 9 \mathrm{me} 2$ expression was associated with higher WHO grade. These results indicated that G9a was expressed at higher levels in tumor tissue 

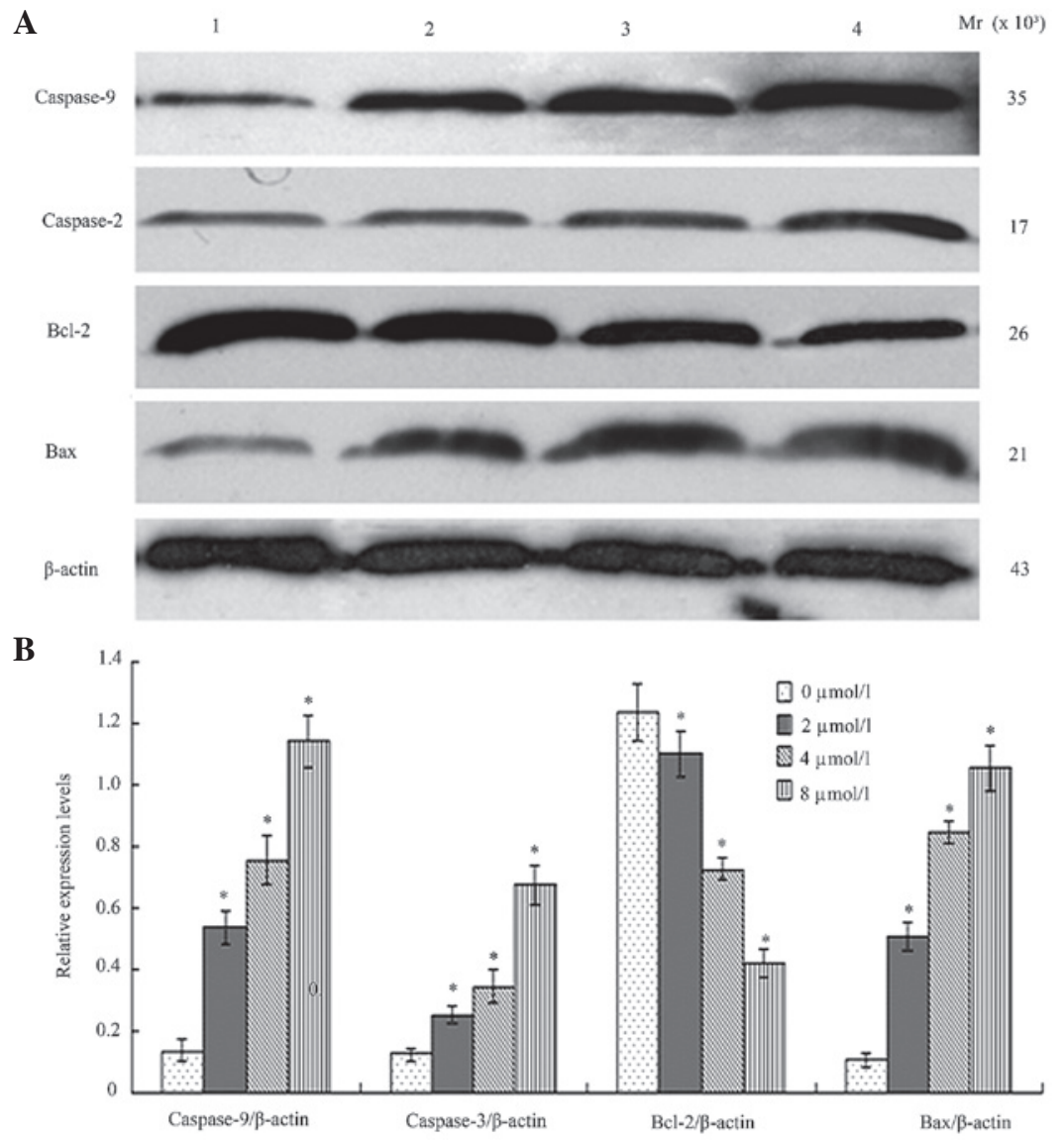

Figure 6. Changes in expression of apoptosis-associated proteins following treatment with BIX-01294 for $24 \mathrm{~h}$. (A) Lane 1, $0 \mu \mathrm{mol} / 1 ; 1$ lane $2,2 \mu \mathrm{mol} / 1 ; 1 \mathrm{ane} 3$, $4 \mu \mathrm{mol} / 1$; and lane 4, $8 \mu \mathrm{mol} / 1$. (B) Quantification of the changes to expression levels. "P<0.05 vs. $0 \mu \mathrm{mol} / 1$.

samples than in normal tissue samples, which may be targeted in therapeutic strategies. Wu et al (9) used depsipeptide to downregulate G9a and SUV39H1 expression, leading to a decrease in $\mathrm{H} 3 \mathrm{~K} 9 \mathrm{me} 2 / 3$ in the promoter region of $P 16$. The enrichment of DNMT1 decreased, DNA was demethylated, P16 was expressed and the proliferation of tumor cells was inhibited.

BIX-01294 is a selective artificial inhibitor of G9a. Kondo et al (3) demonstrated that following BIX-01294 treatment, the activity of G9a and H3K9 methylation decreased, leading to P16 and RASSF1A expression and marked inhibition of PC3 prostate cancer cell growth (3). In the present study, following treatment with different concentrations of BIX-01294 (1, 2, 4 and, $8 \mu \mathrm{mol} / \mathrm{l})$ for $24 \mathrm{~h}$, the proliferation rates of $\mathrm{U} 251$ were $94.12 \pm 3.41,78.83 \pm 2.25,53.68 \pm 2.54$ and $21.04 \pm 2.07 \%$, respectively, which indicated there was a significant concentration-dependent increase. As the treatment time increased, the proliferation rate decreased. Following treatment with different concentrations of BIX-01294 $(1,2,4$ and $8 \mu \mathrm{mol} / \mathrm{l})$ for $24 \mathrm{~h}$, the apoptosis rates of U251 were $3.67 \pm 1.42,16.42 \pm 5.18$, $35.18 \pm 3.26$ and $57.52 \pm 4.37 \%$, which demonstrated the significant increase in apoptosis in a concentration-dependent manner.

Apoptosis is the spontaneous process of programmed cell death, whose generation is under rigorous control in the body. The expression and regulation of the Bcl-2 family is important in signal transduction pathways and apoptosis. The Bcl-2 family includes two types of protein, those that are anti-apoptotic, including Bcl-2, B-cell lymphoma-extra large,
Bcl-2-like protein 2, myeloid cell leukemia-1 and Bcl-2-related protein A1 and pro-apoptotic proteins, including Bax, Bcl-2 homologous antagonist/killer, BH3 interacting-domain death agonist and Bcl-2-associated death promoter (17). Bcl-2 and $B a x$ are the representative anti-apoptotic and pro-apoptotic gene in Bcl-2 family, respectively. Bcl-2 inhibits apoptosis of tumor cells induced by different factors. Bax forms an apoptosis complex and activates caspase-9, which subsequently activates the downstream effector proteins, including caspase-3, caspase-6 and caspase-7 (18). It was observed that following BIX-01294 treatment, Bcl-2 protein expression was downregulated, while Bax expression was upregulated. Apoptosis-associated proteins caspase- 9 and caspase- 3 were upregulated, which resulted in cell apoptosis.

G9a is able to monomethylate and dimethylate H3K9, while trimethylation is reduced when incubated in vitro for an extended amount of time. G9a and GLP in mouse euchromatin is dependent on the heterodimer formed by the SET domain, which may catalyze the production of $\mathrm{H} 3 \mathrm{~K} 9 \mathrm{me} 2$ and $\mathrm{H} 3 \mathrm{~K} 9 \mathrm{me} 1$, enrich heterochromatin protein 1 in euchromatin and mediate transcriptional repression (19). Knock-out of $G 9 a$ in mice reduced $\mathrm{H} 3 \mathrm{~K} 9 \mathrm{me} 2$ which led to the silencing of 167 genes that have enrichment of $\mathrm{H} 3 \mathrm{~K} 9 \mathrm{me} 2$ on the promoter (14). The present study observed that following BIX-01294-induced inhibition of G9a activity, methylation of $\mathrm{H} 3 \mathrm{~K} 9 \mathrm{mel}$ and $\mathrm{H} 3 \mathrm{~K} 9 \mathrm{me} 2$ was downregulated, however, the expression of $\mathrm{H} 3 \mathrm{~K} 9 \mathrm{me} 3$ and Act-H3 is less altered, which is consistent with monomethylation and dimethylation and lacking trimethylation. 


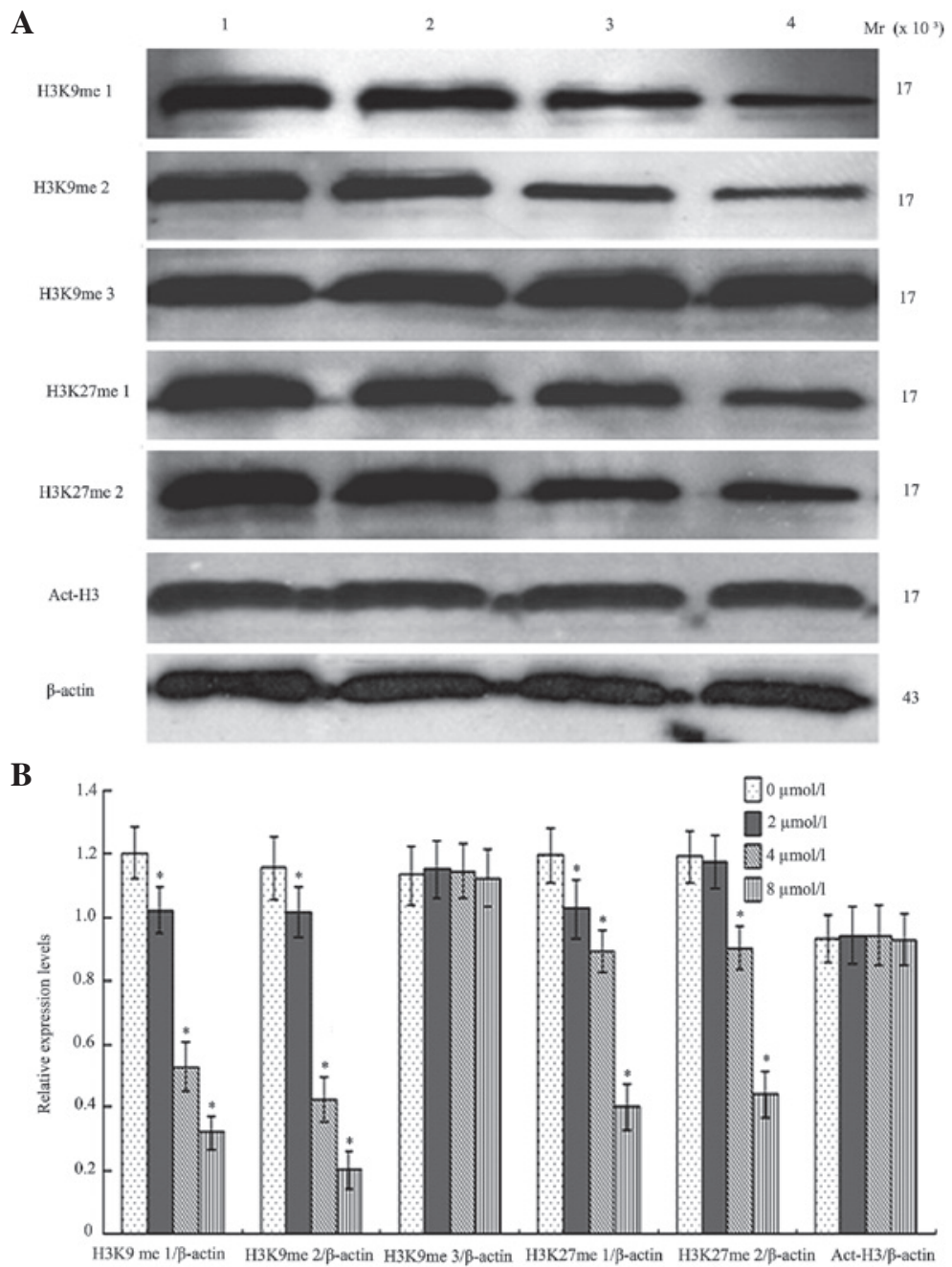

Figure 7. Changes in histone expression following treatment with BIX-01294 for $24 \mathrm{~h}$. (A) Lane 1, $0 \mu \mathrm{mol} / 1$; lane $2,2 \mu \mathrm{mol} / 1$; lane $3,4 \mu \mathrm{mol} / 1$; and lane 4 , $8 \mu \mathrm{mol} / 1$. (B) Quantification of the altered expression level. ${ }^{*} \mathrm{P}<0.05$ vs. $0 \mu \mathrm{mol} / 1$.

H3K27me3 was considered to be associated with transcriptional inhibition. Following trimethylation of H3K27, the protein regulator of cytokinesis 1 complex combined with the specific gene locus, then inhibited the enrichment of transcription activators, silenced tumor suppressor genes and led to carcinoma. Enhancer of zeste homolog 2, the histone methyltransferase catalyzing H3K27 trimethylation, is expressed in numerous tumors, including glioma, which was associated with development and poor prognosis $(20,21)$. However, less research has been conducted on H3K27me1 and H3K27me2. Previous studies demonstrated that in the embryonic stem cell line with deletion of $G 9 a$, the methylation of the 27th lysine in $H 3$ decreased and polycomb repressive complex 2 has an important role in this process $(22,23)$. It was observed that following BIX-01294 treatment to inhibit G9a activity, the methylation of H3K27me1 and H3K27me2 decreased significantly, which suggested that G9a had the ability to methylate $\mathrm{H} 3 \mathrm{~K} 27$, however, this remains to be investigated in a clinical setting.

In conclusion, the present study observed that BIX-01294 inhibits the proliferation of glioma cells and induces apoptosis. Further study demonstrated that the alteration of methylation of $\mathrm{H} 3 \mathrm{~K} 9$ and $\mathrm{H} 3 \mathrm{~K} 27$ resulted in changes in chromosomal conformation, which may be an underlying mechanism of inhibition of tumor cells proliferation. BIX-01294 may be a potential novel therapeutic agent in the treatment of glioma.

\section{Acknowledgements}

This work was supported by the Natural Science Foundation of Fujian Province (grant no. 2016J01484) and the Introductive Major Project of Science Research Foundation of Fujian Province (grant no. 201212004).

\section{References}

1. Parsons DW, Jones S, Zhang X, Lin JC, Leary RJ, Angenendt P, Mankoo P, Carter H, Siu IM, Gallia GL, et al: An integrated genomic analysis of human glioblastoma multiforme. Science 321: 1807-1812, 2008.

2. Huang J, Dorsey J, Chuikov S, Pérez-Burgos L, Zhang X, Jenuwein T, Reinberg D and Berger SL: G9a and Glp methylate lysine 373 in the tumor suppressor p53. J Biol Chem 285: 9636-9641, 2010

3. Kondo Y, Shen L, Ahmed S, Boumber Y, Sekido Y, Haddad BR and Issa JP: Downregulation of histone H3 lysine 9 methyltransferase G9a induces centrosome disruption and chromosome instability in cancer cells. PLoS One 3: e2037, 2008.

4. Fuller GN and Scheithauer BW: The 2007 Revised World Health Organization (WHO) Classification of Tumours of the Central Nervous System: newly codified entities. Brain Pathol 17: 304-307, 2007. 
5. Lin X, Huang Y,Zou Y, Chen X and Ma X: Depletion of G9a gene induces cell apoptosis in human gastric carcinoma. Oncology Reports 35: 3041-3049, 2016.

6. McGarvey KM, Fahrner JA, Greene E, Martens J, Jenuwein T and Baylin SB: Silenced toumor stressor genes reactivated by DNA demethylation do not return to a fully euchromatic chromati state. Cancer Res 66: 3541-3549, 2006.

7. Stewart MD, Li J and Wong J: Elationship between histone H3 lysine 9 methylation, transcription repression, and heterochromatin protein 1 recruitment. Mol Cell Biol 25: 2525-2538, 2005.

8. El Gazzar M, Yoza BK, Chen X, Hu J, Hawkins GA and McCall CE: G9a and HP1 couple histone and DNA methylation to TNFalpha transcription silencing during endotoxin tolerance. J Biol Chem 283: 32198-32208, 2008.

9. Wu LP, Wang X, Li L, Zhao Y, Lu S, Yu Y, Zhou W, Liu X, Yang J, Zheng Z, et al: Histone deacetylase inhibitor depsipeptide activates silenced genes through decreasing both $\mathrm{CpG}$ and $\mathrm{H} 3 \mathrm{~K} 9$ methylation on the promoter. Mol Cell Biol 28: 3219-3235, 2008.

10. Cai L, Ma X, Huang Y, Zou Y and Chen X: Aberrant histone methylation and the effect of Suv39H1 siRNA on gastric carcinoma. Oncol Rep 31: 2593-2600, 2014.

11. Cattaneo F and Nucifora G: EVI1 recruits the histone methyltransferase SUV39H1 for transcription repression. J Cell Biochem 105: 344-352, 2008

12. Goyama S, Nitta E, Yoshino T, Kako S, Watanabe-Okochi N Shimabe M, Imai Y, Takahashi K and Kurokawa M: EVI-1 interacts with histone methyl transferases SUV39H1 and G9a for transcriptional repression and bone marrow immortalization. Leukemia 24: 81-88, 2010.

13. Wu H, Chen X, Xiong J, Li Y, Li H, Ding X, Liu S, Chen S, Gao S and Zhu B: Histone methyltransferase G9a contributes to H3K27 methylation in vivo. Cell Res 21: 365-367, 2011.

14. Yokochi T, Poduch K, Ryba T, Lu J, Hiratani I, Tachibana M, Shinkai Y and Gilbert DM: G9a selectively represses a class of late-replicating genes at the nuclear periphery. Proc Natl Acad Sci USA 106: 19363-19368, 2009.
15. Zou Y, Ma X, Huang Y, Hong L and Chiao JW: Effect of phenylhexyl isothiocyanate on aberrant histone $\mathrm{H} 3$ methylation in primary human acute leukaemia. J Hematol Oncol 5: 36, 2012.

16. Chen Y, Luo J, Chen B, Wang J and Zou S: Expression of histone methyltransferase G9a and clinical significance in extrahepatic cholangiocarcinoma. Chin-Ger J Clin Oncol 7: 10-13, 2008.

17. Sitailo LA, Jerome-Morais A and Denning MF: Mcl-1 functions as major epidermal survival protein required for proper keratinocyte differentiation. J Invest Dermatol 129: 1351-1360, 2009.

18. Theofilas P, Bedner P, Hüttmann K, Theis M, Steinhäuser C and Frank S: The proapoptotic BCL-2 homology domain 3 -only protein Bim is not critical for acute excitotoxic cell death. J Neuropathol Exp Neurol 68: 102-110, 2009.

19. Tachibana M, Matsumura Y, Fukuda M, Kimura $H$ and Shinkai Y: G9a/GLP complexes independently mediate H3K9 and DNA methylation to silence transcription. EMBO J 27: 2681-2690, 2008

20. Zhang YB, Niu HT, Chang JW, Dong GL and Ma XB: EZH2 silencing by RNA interference inhibits proliferation in bladder cancer cell lines. Eur J Cancer Care (Engl) 20: 106-112, 2011.

21. Bryant RJ, Winder SJ, Cross SS, Hamdy FC and Cunliffe VT: The Polycomb group protein EZH2 regulates actin polymerization in human prostate cancer cells. Prostate 68: 255-263, 2008.

22. Ma DK, Chiang CH, Ponnusamy K, Ming GL and Song H: G9a and Jhdm2a regulate embryonic stem cell fusion-induced reprogramming of adult neural stem cells. Stem Cells 26: 2131-2141, 2008.

23. Ikegami K, Iwatani M, Suzuki M, Tachibana M, Shinkai Y, Tanaka S, Greally JM, Yagi S, Hattori N and Shiota K: Genome-wide and locus-specific DNA hypomethylation in G9a deficient mouse embryonic stem cells. Genes Cells 12: $1-11,2007$ 